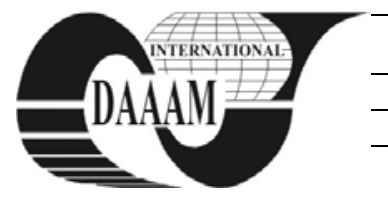

Annals of DAAAM for 2011 \& Proceedings of the 22nd International DAAAM Symposium, Volume 22, No. 1, ISSN $1726-9679$ ISBN 978-3-901509-83-4, Editor B. Katalinic, Published by DAAAM International, Vienna, Austria, EU, 2011 Make Harmony between Technology and Nature, and Your Mind will Fly Free as a Bird Annals \& Proceedings of DAAAM International 2011

\title{
TAGUCHI METHOD FOR ROBUST DESIGN IN QUALITY MANAGEMENT
}

\author{
BOCA, G[ratiela] D[ana]
}

\begin{abstract}
The following case study uses Taguchi's method, to integrate product and process design for planetary gear system using sound and vibration problem which still remain an unsolved problem yet. The paper present author research work to identify some solutions to improve quality system and identify the connection between noise and quality. The method permit for both product and process design stage to improve product manufacturability and reliability by making products sensitive to environmental conditions and component variation. Taguchi is a quick method to improve product quality just design into product from the start data and not change anything else.
\end{abstract}

Key words: Taguchi method, design, quality, noise, robust design

\section{INTRODUCTION}

In recent years there have been an increasing demand for more comfort concerning noise.

As we know quality product depend not only of manufactured tolerance, material but also in the last few years a lot of research investigations show that the vibration and acoustic problems can also influence the gear quality. Because the trend is new it is a good opportunity to give a more carefully attention to this problem. As a matter of fact that noise problem influence not only the environment but also can be used as a tool to predict gears fallures. Manufacturing Quality is very important, so the gears wear and contact zone become one of the emerging area in gear technology. My research was focus in low noise design because the dynamic analysis can give us the final solutions which are essential for eliminating noise and vibration problems of the production. Until now a lot of investigations found different solutions for the improvement of quality, but the problem of low design solution it is still remaining an open field. Using the theoretical knowledge we can take in consideration the noise as a source for entire machine and identify whıch component from machine has a major influence and improve the manufacturing quality.

The methods are useful for the determination of sound influence and also in discovering the damage and the future failure of transmission. The theoretical model for the wear and manufacturing quality can also give a solution from technical point of view. Finite Element Method give using the virtual simulation the answer to different situation which can be find in practice. Not at last this theoretical model can be a important tool for the design machine and for a better improvement of quality.

So it is useful to discover and prevent the wear gear, or to use the low noise design of machine and implemented in this way a higher quality. Robust design it is used in engineering to improve productivity during research and development so high quality products can be produced quickly and at low cost. The idea behind robust design is to improve the quality of a product and minimize the effects without eliminating the causes.

\section{OBJECT OF RESEARCH}

The following case study uses Taguchi's method, to integrate product and process design for planetary gear system and his sound and vibration problem which still remain an unsolved problem yet. The mechanism by which the noise is transmitted from the source through the structure of the machine are shown on the third ring from the inside of the diagram ring denotes the processes by which he noise is radiated from the surface of the machine (figure 1).

The diagram shows that every type of noise and transmission has its own unique characteristics To diagnose a machine with various noise sources and transmission paths, it is necessary to examine its entire noise generation chain, for gears transmission the noise reduction was the first priority.

The primary noise reduction was affecting the gear meshing, but also the design and development places (chaise of helix angel, gearing precision).

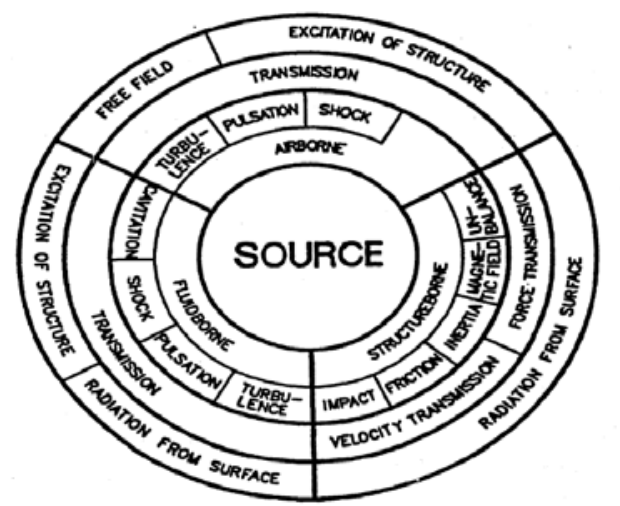

Fig. 1. Basic model of noise generation in machines

The solution from technical point of view was an additional capsule which can protect the machine noise. Also using the design principle of splitting the tasks between force transmission and structure borne noise transmission has as a result a new gear, contains strong inner sitting which enables a short distance, between bearings and a direct force transmission and data also walls designed as capsules. Starting from the diagram and investigating the gears noises sources we have not resolved yet the noise problem.

A careful investigation show us that design process is highly complex because of the various criteria which must be satisfied, restrictions complied with other conditions, standards, production options must to be maintained.

Even the design solution resolve a part of noise problems, there are other factors which can influence the noise problem.

The experiment that is being conducted seeks to determine a method to select the optimal solution for manufacture.

The primary design objective didn't take in consideration the noise, the research work come to give some alternatives from design point of view. 


\section{RESEARCH METHODOLOGY}

Following Taguchi's method, two type of factors for planetary gears was selected montage of solar pinion and noise factors. To achieve the new product quality by design, the following stage-steps process was taken in consideration: system design, parameter design and tolerance design.

For the parameter design two factors that affect the product functional characteristics control factors and noise factors was taken in consideration. Noise factors are factors that are difficult or impossible or too expensive to be control.

For our product three type of noise factors was identify: outer noise, inner noise and between product noise (Figure 2).

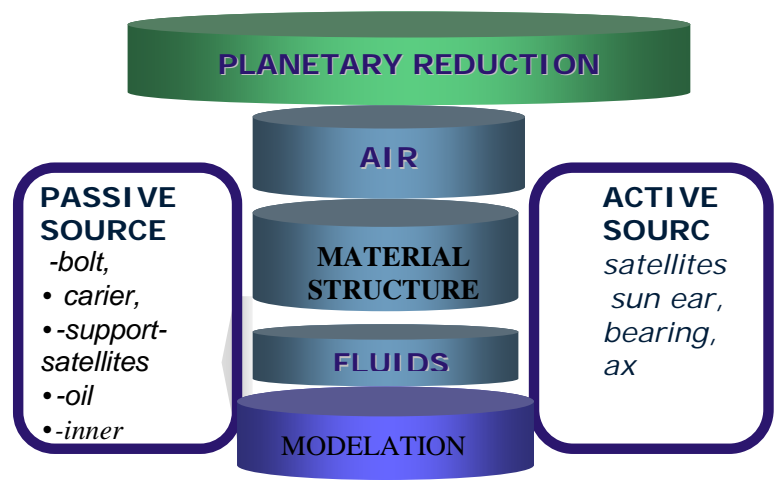

Fig. 2. Noise sources for planetary gear

The generater sources of sounds for planetary gears are (2):

- air source - air-pocketing, because of the air between the tooth ,

- material structure source - depends of material , geometrical characteristics of the tooth,

- liquid source -considering the oil used for lubrification, also from the flotting planetary gear as a new solution and the bearings from the rigide solution.

Another sources for the planetary gears which can generate the sounds and who can be use in the same time for the identification of the reliability of the system are present in sources can be: activ: stift,carrier, suport-satellites, oil lubrifiant, inner with internal tooth and passive: satellites, solar gear, bearings, ax tree.

\section{RESULTS}

Several types of machine problems can be diagnosed by detailed examination of these sidebands. The conclusion regarding the influence of flank form yielding to sound formation show that a low quality of the coordination are essentially, as well production-conditional deviations of debit geometry like in the following distinguished fazes:

-flank-irregularities distinguish themselves through periodicities, that are independently from the tooth intervention frequency;

-index errors, that level sharpens with the harmonic of speed lie;

-intervention angle mistakes and reason circle mistakes do themselves a notice particularly with low burdens,

-higher specific tooth causes an increase of the sound level with the specific tooth by virtue;

-distortions from waves, stores and casings on the basis from softness to vibrations.

\section{CONCLUSIONS}

In this paper author have presented experimental tests for two constructive planetary gears with free mounting with rigid pinion solar using Taguchı method.

The influence of Manufacturing Quality upon gearstransmission using low noise design can give us a solution for increasing reliability of the planetary gears, a way for a better maintenance of the system machinery or a permanent and quickly diagnosis for the new born signature sign of wear. Experimental data obtained for the different gears were compared with data obtained using virtual modeling and simulation.

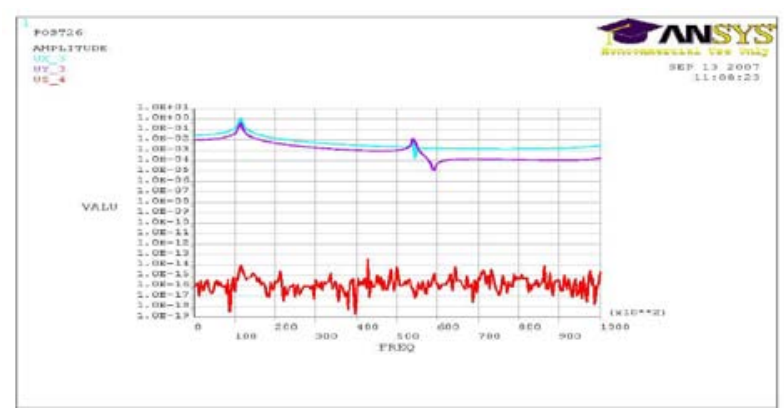

Fig. 3. Complete modal analyze USUM for planetary gears

Planetary gear dynamics with free mounting solar gear give us detailed solutions of the influence of vibration transmission to the system during operation (Figure 3). Quality noise study was important because it was possible to analyze how the behavior and transmission of vibrations arising from the actions to fatigue on the planetary gear reduction box during operation. The significant frequency value obtain for planetary gear using rigid solution for solar gear is $\mathrm{f}=100 \mathrm{~Hz}$ with a vibration amplitude with a variable range of high frequencies UZ (figure 4).

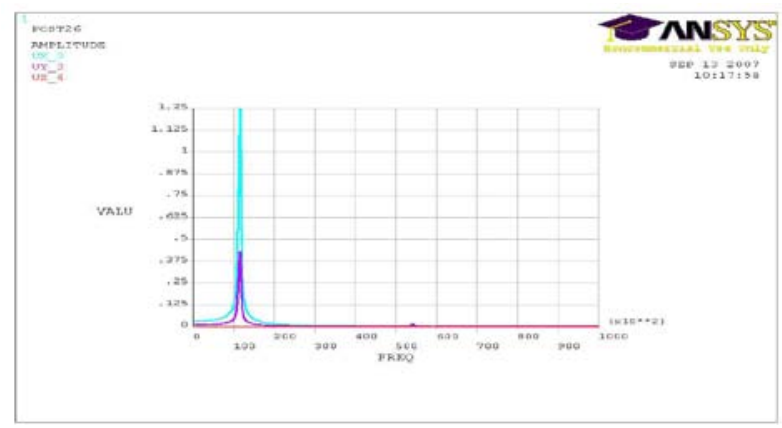

Fig. 4. Significant frequency for planetary gears

\section{ACKNOWLEDGEMENTS}

The paper present the results obtain in ITW Clausthal under the research grant, supervise by prof.dr. PAY Eugen Phd.h.c. from North University Baia Mare, Romania and prof.dr. DIETZ Peter Phd.hc from ITW Clausthal, Germany. The model of planetary gear was realize under the supervise of dipl.eng. Elie NSENGA from IMW Clausthal.

\section{REFERENCES}

Albers, A., Weiler, H. (2008), Impact of Distribution Functions of Input Parameters on the Quality of Robustness Analysis in Simulation. Wiesbaden, ISBN 1-874376-14-X

Bangert, C., Jiang, J.: (2006), Optimization and robustness analysis with deep drawing simulation, INPRO Workshop Robust Processes with Modern Steels, Berlin

Dietz, P. (2005), Experimental determination of the tooth warring firmness, DIN 28919-2005

Dietz, P. (2003), Hub does not wave anything new to investigate, Institute for manufacturing engineering, Clausthal

Dietz, P., Haje, D.(2000), Development of low noise products computer aided guidance for the designer, International Conference Design 2000, Dubrovnik

Hammer M. \& Stanton S. (1996) The reengineering revolution, Handbook. London: Hammersmith 